\title{
Nefrolitiazisli Asemptomatik Bir Olgunun İdrar Kültüründen İzole Edilen Mukoid Salmonella sp. Suşunun Tür Düzeyinde Tanımlanmasında PCR Yönteminin Değeri
}

\section{The Value of PCR Method in the Species-Level Identification of a Mucoid Salmonella sp. Strain Isolated from the Urine Culture of a Case with Asymptomatic Nephrolithiasis}

\author{
Fulya BAYINDIR BILMAN ${ }^{1}$, Elçin GÜNAYDIN² ${ }^{2}$, Mine TURHANOĞLU ${ }^{1}$, Ali AKKOÇ ${ }^{3}$ \\ ${ }^{1}$ Diyarbakır Eğitim ve Araştırma Hastanesi, Mikrobiyoloji Laboratuvarı, Diyarbakır. \\ ${ }^{1}$ Diyarbakir Training and Research Hospital, Microbiology Laboratory, Diyarbakir, Turkey. \\ ${ }^{2}$ Etlik Veteriner Kontrol Merkez Araştırma Enstitüsü, Bakteriyolojik Teşhis Laboratuvarı, Ankara. \\ ${ }^{2}$ Etlik Veterinary Control Center Institute, Bacteriology Laboratory, Ankara, Turkey. \\ ${ }^{3}$ Diyarbakır Eğitim ve Araştırma Hastanesi, Üroloji Kliniği, Diyarbakır. \\ ${ }^{3}$ Diyarbakir Training and Research Hospital, Urology Department, Diyarbakir, Turkey.
}

Geliş Tarihi (Received): 01.04.2013 • Kabul Ediliş Tarihi (Accepted): 18.06.2013

\section{ÖZET}

Salmonella cinsinin üyesi olan bakterilerin koloni yapıları genellikle düzgün (smooth, S) özellik göstermektedir. Bu nedenle literatürde mukoid görünümde koloni oluşturan Salmonella suşlarına çok nadiren rastlanmaktadır. Mukoid yapıya sahip olan suşların tür düzeyinde tanımlanması konvansiyonel yöntemlerle zor olmaktadı; zira mukus tabakası bakterinin antijenik reaksiyonlara tepki vermesini engellemektedir. Bu çalışmanın amacı, kaba (rough, R) veya mukoid (M) formda Salmonella izolatları ile karşısşılan durumlarda polimeraz zincir reaksiyonu ile serotiplendirmenin hızlı ve güvenilir bir yöntem olduğunu vurgulamaktır. Hastanemizde nefrolitiazis tanısı ile takip edilen 17 yaşındaki bir kadın hastanın idrar kültüründe $100.000 \mathrm{cfu} / \mathrm{ml}$ mukoid koloni oluşturan gram-negatif basil üremiştir. İzolat, biyokimyasal testler ve Vitek 2 (bioMérieux, Fransa) otomatize sistemi ile Salmonella sp. olarak tanımlanmış, bilinen antiserumlarla yapılan aglütinasyon testlerinde negatif sonuç alınmıştır. İzolatın mukoid olmasından dolayı aglütinasyonun oluşamadığı düşünülmüştür. Tanı, Vitek MS MALDI-TOF (bioMérieux, Fransa) analiz yöntemi ile de Salmonella sp. olarak doğrulanmış, ancak yine tür düzeyinde tanımlama yapılamamıstır. Mukoid koloninin Salmonella sp. olduğu, invA primerleri ile yapılan cinse özgül PCR yönteminde yaklaşık 
284 baz çifti (bç) büyüklüğünde PCR amplikonunun oluşması sonucu doğrulanmıştır. Ardından, O:B (O:4), O:C1 (O:7), O:C2-C3 (O:8), O:D (O:9, O:9,46, O:9,46,27), O:E (O:3,10, O:3,19) somatik antijenlerinin tespit edilebildiği bir multipleks PCR (mPCR) ile serogruplandırma yapılmıştır. Mukoid Salmonella türünün yaklaşık 615 bç büyüklüğünde bant oluşturduğu ve $D$ grubu içinde yer aldığı tespit edilmiştir. Bu suşun, insanlardan sıklıkla izole edilen D1 grubunda yer alıp almadığını tespit etmek için, O:D1(O:9) ve O:E1 $(3,10)$ somatik antijenlerinin belirlenebildiği bir diğer mPCR uygulanmış ve yaklaşık 624 bç büyüklüğünde oluşturduğu bant ile izolatın D1 grubunda yer aldığı belirlenmiştir. D1 grubunda yer alan mukoid Salmonella türünün faz-1 flajellar antijenlerinin belirlenmesi için uygulanan mPCR sonucu, izolat Salmonella Enteritidis (1,9,12:g,m:-) olarak tiplendirilmiştir. Disk difüzyon yöntemi ile CLSI'nın önerilerine uygun olarak yapılan antibiyotik duyarlıık testinde izolatın ampisilin, siprofloksasin, seftriakson, trimetoprim-sülfametoksazol ve kloramfenikole duyarlı olduğu bulunmuştur. Sonuç olarak, somatik, flajellar antijenlerin eksprese edilmediği, kaba veya mukoid formda Salmonella izolatları ile karşılaşılan durumlarda, PCR yönteminin hızlı ve güvenilir bir alternatif yöntem olarak, konvansiyonel serotiplendirmeye yardımcı olabileceği ortaya konmuştur.

\section{Anahtar sözcükler: Mukoid Salmonella; Salmonella Enteritidis; polimeraz zincir reaksiyonu.}

\section{ABSTRACT}

Colonies of the Salmonella strains usually show a smooth (S) character. Therefore, Salmonella strains producing mucoid colony are very rarely encountered in the literature. Identification of the mucoid Salmonella strains to the species level is difficult via conventional methods, since the mucus layer does not allow the bacterium to respond to the antigenic reactions. In this study we aimed to emphasize the identification of Salmonella serotypes by the polymerase chain reaction (PCR) when rough (R) or mucoid (M) Salmonella isolates are encountered in the laboratory. The urine culture of a 17-year-old female patient revealed growth of $100.000 \mathrm{cfu} / \mathrm{mL}$ gram-negative bacilli in mucoid colony morphology. The isolate was identified as Salmonella sp. by biochemical tests and Vitek 2 (bioMérieux, France) automated identification system. Agglutination tests showed negative reaction with the known antiserums. Absence of agglutination was attributed to the mucoid character of the isolate. Identification of the Salmonella sp. was confirmed by Vitek MS MALDI-TOF (bioMérieux, France) analysis method, however, the serotype of the strain could not be identified. In order to verify that the mucoid colony was Salmonella spp., species-specific PCR was performed using invA primers, and Salmonella sp. identification was verified by observing a 284 base-pair (bp) PCR amplicon. Subsequently, serogrouping was done by multiplex-PCR (mPCR), which could identify the O:B (O:4), O:C1 (O:7), O:C2-C3 (O:8), O:D (O:9, O:9,46, O:9,46,27), and $\mathrm{O}: \mathrm{E}(\mathrm{O}: 3,10, \mathrm{O}: 3,19)$ somatic antigens. It was detected that the mucoid Salmonella sp. formed a band of approximately $615 \mathrm{bp}$ in size and took place in group D. Another mPCR directed towards O:D1(O:9) and O:E1 $(3,10)$ somatic antigens to detect subgroups of group D mucoid Salmonella spp., revealed that the isolate formed a DNA band of approximately $624 \mathrm{bp}$ in size and took place in group D1 which is usually isolated from human. Modified version of another MPCR was used to determine phase-1 flagellar antigen of common Salmonella serovars, as well as to determine the phase-1 flagellar antigen of mucoid Salmonella spp. in group D1. Thus, the isolate was serotyped as Salmonella Enteritidis $(1.9,12: \mathrm{g}, \mathrm{m}:-)$. Antibiotic susceptibility test performed by disc diffusion method in line with the recommendations of CLSI, revealed that the isolate was susceptible to ampicillin, ciprofloxacin, ceftriaxone, trimethoprim-sulfamethoxazole and chloramphenicol. In conclusion, PCR is a reliable and rapid alternative method that contributes to the conventional serotyping of Salmonella when rough or mucoid strains that lack somatic and flagellar antigens, are isolated.

Key words: Mucoid Salmonella; Salmonella Enteritidis; polymerase chain reaction. 


\section{Giriş}

Salmonella türleri, halen dünyada gelişmekte olan/az gelişmiş ülkelerde hemen her mevsimde su ve besin kaynaklı enfeksiyonlara ve salgınlara yol açmaktadır. Tifo ve enterik ateş gibi ciddi klinik tabloların yanı sıra, bu bakterilerle enfekte kişilerin \%3'ünde kronik taşıyıcılık da ortaya çıkmaktadır. Klinik şüpheli olguların kesin tanısı, kültür, biyokimyasal testler ve serolojik tiplendirme testleri ile yapılmaktadır. EMB (Eosin-MethyleneBlue) agarda tipik olarak laktoz negatif düzgün kenarlı (smooth, S) koloniler oluşturan Salmonella türlerinin, literatürde çok az sıklıkta karşılaşılabilen mukoid bir formunun varlığına da değinilmektedir ${ }^{1,2}$. Hastalık Kontrol Merkezi (CDC) referans laboratuvarına gönderilen idrar izolatları arasında zaman zaman düzgün olmayan kenarlı (rough, R), mukoid (M) ve/veya hareketsiz Salmonella suşlarının saptanabildiği bildirilmektedir². R tipi suşlar polivalan $\mathrm{O}$ grup antiserumları ile zayıf aglütinasyon verirken, $\mathrm{M}$ tipi suşlar herhangi bir $\mathrm{O}$ antiserumu ile aglütinasyon vermemekte; hareketsiz olan suşlar ise herhangi bir flajellar antijen içermemektedir ${ }^{1}$. Bu çalışmanın amacı, nefrolitiazisli bir hastadan izole edilen ve konvansiyonel ve otomatize yöntemlerle tür düzeyinde tanımlanamayan mukoid bir Salmonella suşunun tür düzeyinde tanımlanmasında polimeraz zincir reaksiyonu (PCR) yönteminin değerini vurgulamaktır.

\section{OLGU SUNUMU}

Hastanemizde nefrolitiazis tanısı ile izlenen 17 yaşında bir kadın hastadan alınan idrar kültüründe EMB (Merck, Almanya) ve kanlı agarda (Merck, Almanya) 100.000 cfu/ml yoğun mukoid özellikte bir bakteri üremiş ve yapılan Gram boyamada negatif basiller görülmüştür. Bakteri, TSI (Triple-sugar-iron) agarda $\mathrm{H}_{2} \mathrm{~S}$ ve gaz üretimi; sitrat agarda pozitif ve üreli agarda negatif reaksiyonuna göre Salmonella sp. olarak tanımlanmışıır. izolat, Vitek 2 (bioMérieux, Fransa) otomatize sistemi ile de cins düzeyinde tanımlanmış, ancak tür düzeyinde tanımlama yapılamamıştır. Salmonella serogrup $\mathrm{O}$ antijenleri için polivalan antiserumla ve $\mathrm{O}$ ve $\mathrm{H}$ antijenlerine özgül antiserumlarla yapılan aglütinasyon reaksiyonları negatif sonuç vermiştir. Bu durumun bakteri kolonilerinin aşırı mukoid özellikte olması ile ilişkili olduğu ve aglütinasyonun engellendiği kanısına varılmıştır. Bunun üzerine tanımlama için Vitek MS MALDI-TOF yöntemi (bioMérieux, Fransa) kullanılmış; sonuç Salmonella sp. olarak alınmış ve tür adı yine belirlenememiştir. Mukoid koloni, ancak PCR yöntemi ile tür düzeyinde tanımlanabilmiştir.

\section{PCR Yöntemi}

Mukoid koloninin Salmonella sp. olduğunun doğrulanması için öncelikle invA primerleri kullanılarak cinse özgül PCR gerçekleştirildi ${ }^{3}$ (Tablo I). Reaksiyon karışımı; $2.5 \mu \mathrm{l} 10 \mathrm{X}$ PCR tamponu ( $\mathrm{MgCl}_{2}$ içermeyen), $1.5 \mu \mathrm{MgCl}_{2}(25 \mathrm{mM}), 0.2 \mu \mathrm{lNTP}(25 \mathrm{mM})$, her bir primerden (10 pmol/ $\mu \mathrm{l}$ ) 0.5'er $\mu \mathrm{l}, 0.25 \mu \mathrm{l} \mathrm{Taq} \mathrm{DNA} \mathrm{polimeraz}(5 \mathrm{U} / \mu \mathrm{l}$, Fermentas; EP402), $18.55 \mu \mathrm{l}$ deionize su ve $1 \mu \mathrm{l}$ kalıp (template) olmak üzere toplam hacim 25 $\mu$ l olacak şekilde hazırlandı. Reaksiyon protokolü; $94^{\circ} \mathrm{C}^{\prime} \mathrm{de} 2 \mathrm{dk}$ ön denatürasyon, 30 


\begin{tabular}{|c|c|c|c|}
\hline Primer adı & Baz dizilimi & Ürün Büyüklüğü & Kaynak \\
\hline \multicolumn{4}{|c|}{ Salmonella cinsine özgül PCR } \\
\hline invA1 & 5'-GTGAAATTATCGCCACGTTCGGGCAA-3' & 284 bç & \multirow[t]{2}{*}{ Rahn ve ark. ${ }^{3}$} \\
\hline invA2 & 5'-TCATCGCACCGTCAAAGGAACC-3' & & \\
\hline \multicolumn{4}{|c|}{ Salmonella serogrup multipleks PCR } \\
\hline F-tyvD & 5'-GAGGAAGGGAAATGAAGCTTTT-3' & 615 bç & \multirow{10}{*}{$\begin{array}{l}\text { Herrera-Leon } \\
\text { ve ark. }{ }^{4}\end{array}$} \\
\hline R-tyvD & 5'-TAGCAAACTGTCTCCCACCATAC-3' & & \\
\hline F-wzxB & 5'-GGCATATATTTCTGTATTCGCG-3' & 230 bç & \\
\hline$R-w z x B$ & 5'-GCCTTAATTAAGTAAGTTAGTGGAAGC-3' & & \\
\hline $\mathrm{F}-\mathrm{wzxC} 1$ & 5'-CAGTAGTCCGTAAAATACAGGGTGG-3' & 483 bç & \\
\hline $\mathrm{R}-\mathrm{wzxC} 1$ & 5'-GGGGCTATAAATACTGTGTTAAATTCC-3' & & \\
\hline F-wzxC2-C3 & 5'-ACTGAAGGTGGTATTTCATGGG-3' & 154 bç & \\
\hline $\mathrm{R}-\mathrm{wzxC} 2-\mathrm{C} 3$ & 5'-AAGACATCCCTAACTGCCCTGC-3' & & \\
\hline F-wzxE & 5'-TAAAGTATATGGTGCTGATTTAACC-3' & 345 bç & \\
\hline R-wzxE & 5'-GTTAAAATGACAGATTGAGCAGAG-3' & & \\
\hline \multicolumn{4}{|c|}{ Salmonella D1-E1 gruba özgül multipleks PCR } \\
\hline F-D1 & 5'-ATGGGAGCGTTTGGGTTC-3' & 624 bç & \multirow[t]{4}{*}{ Hong ve ark. } \\
\hline R-D1 & 5'-CGCCTCTCCACTACCAACTTC-3' & & \\
\hline F-E1 & 5'-GATAGCAACGTTCGGAAATTC-3' & 281 bç & \\
\hline R-E1 & 5'-CCCAATAGCAATAAACCAAGC-3' & & \\
\hline \multicolumn{4}{|c|}{ Salmonella Faz-1 multipleks PCR } \\
\hline F-Sense-60 & 5'-GCAGATCAACTCTCAGACCCTGGG-3' & & \multirow{9}{*}{$\begin{array}{l}\text { Herrera-Leon } \\
{\text { ve } \text { ark }^{6}}^{6}\end{array}$} \\
\hline Antisense-i & 5'-ATAGCCATCTTTACCAGTTCC-3' & 250 bç & \\
\hline Antisense-z10 & 5'-CGTCGCAGCTTCTGCAACC-3' & $400 \mathrm{bç}$ & \\
\hline Antisense-I, v & 5'-CCTGTCACTTTCGTGGTTAT-3' & $300 \mathrm{bç}$ & \\
\hline Antisense-r & 5'-AAGTGACTTTTCCATCGGCTG-3' & 275 bç & \\
\hline $\mathrm{F}-\mathrm{G}$ & 5'-GTGATCTGAAATCCAGCTTCAAG-3' & $500 \mathrm{bç}$ & \\
\hline R-G & 5'-AAGTTTCGCACTCTCGTTTTTGG-3' & & \\
\hline F-Sdf-I & 5'-TGTGTTTTATCTGATGCAAGAGG-3' & $300 \mathrm{bç}$ & \\
\hline R-Sdf-I & 5'-CGTTCTTCTGGTACTTACGATGAC-3' & & \\
\hline
\end{tabular}

döngü $94^{\circ} \mathrm{C}^{\prime}$ de $30 \mathrm{sn}, 57^{\circ} \mathrm{C}^{\prime}$ de $40 \mathrm{sn}, 72^{\circ} \mathrm{C}^{\prime}$ de 30 sn birleşme, $72^{\circ} \mathrm{C}^{\prime}$ de $5 \mathrm{dk}$ son uzama şeklinde uygulandı. Mukoid koloninin, yaklaşık 284 baz çifti (bç) büyüklüğünde PCR amplikonu oluşturduğu ve Salmonella sp. olduğu doğrulandı (Şekil 1).

Ardından, O:B (O:4), O:C1 (O:7), O:C2-C3 (O:8), O:D (O:9, O:9,46, O:9,46,27), O:E $(\mathrm{O}: 3,10, \mathrm{O}: 3,19)$ somatik antijenlerinin tespit edilebildiği bir multipleks PCR ile 


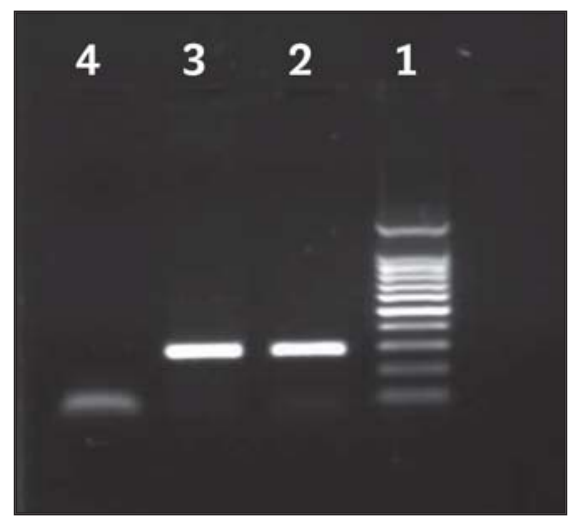

Şekil 1. Salmonella cinsine özgül PCR görüntüsü [Hat 1: 100 bç DNA belirteci (Fermentas, SM0241); Hat 2: Salmonella Typhimurium; Hat 3: Mukoid Salmonella izolatı; Hat 4: Negatif kontrol $\left.\left(d_{d d H_{2}} \mathrm{O}\right)\right]$.

serogruplandırma yapıldı ${ }^{4}$ (Tablo I). Reaksiyon karışımı; $2.5 \mu$ l 10X PCR tamponu $\left(\mathrm{MgCl}_{2}\right.$ içermeyen), $3 \mu \mathrm{IgCl}_{2}(25 \mathrm{mM}), 0.2 \mu \mathrm{dNTP}(25 \mathrm{mM})$, her bir primerden $(5 \mathrm{pmol} / \mu \mathrm{l})$ $0.5^{\prime}$ er $\mu \mathrm{l}, 0.25 \mu \mathrm{l}$ Taq DNA polymerase (5 U/ $\mu \mathrm{l}$, Fermentas; EP402), $13.05 \mu$ l deionize su, $1 \mu \mathrm{l}$ kalıp olmak üzere toplam hacim $25 \mu$ l olacak şekilde hazırlandı. Reaksiyon protokolü; $94^{\circ} \mathrm{C}^{\prime}$ de $2 \mathrm{dk}$ ön denatürasyon, 30 döngü $94^{\circ} \mathrm{C}^{\prime}$ de $30 \mathrm{sn}, 58^{\circ} \mathrm{C}^{\prime}$ de $40 \mathrm{sn}, 72^{\circ} \mathrm{C}^{\prime}$ de 30 sn birleşme, $72^{\circ} \mathrm{C}^{\prime}$ de $5 \mathrm{dk}$ son uzama şeklinde uygulandı. Buna göre mukoid Salmonella izolatının yaklaşık 615 bç büyüklüğünde bant oluşturduğu ve D grubu içinde yer aldığı tespit edildi (Şekil 2).

D grubunda yer alan mukoid Salmonella suşunun, insandan sıklıkla izole edilen D1 grubunda yer alıp almadığını tespit etmek için, O:D1(O:9) ve O:E1(3,10) somatik antijenlerinin belirlenebildiği bir multipleks PCR uygulandı ${ }^{5}$ (Tablo I). Reaksiyon karışımı; 2.5

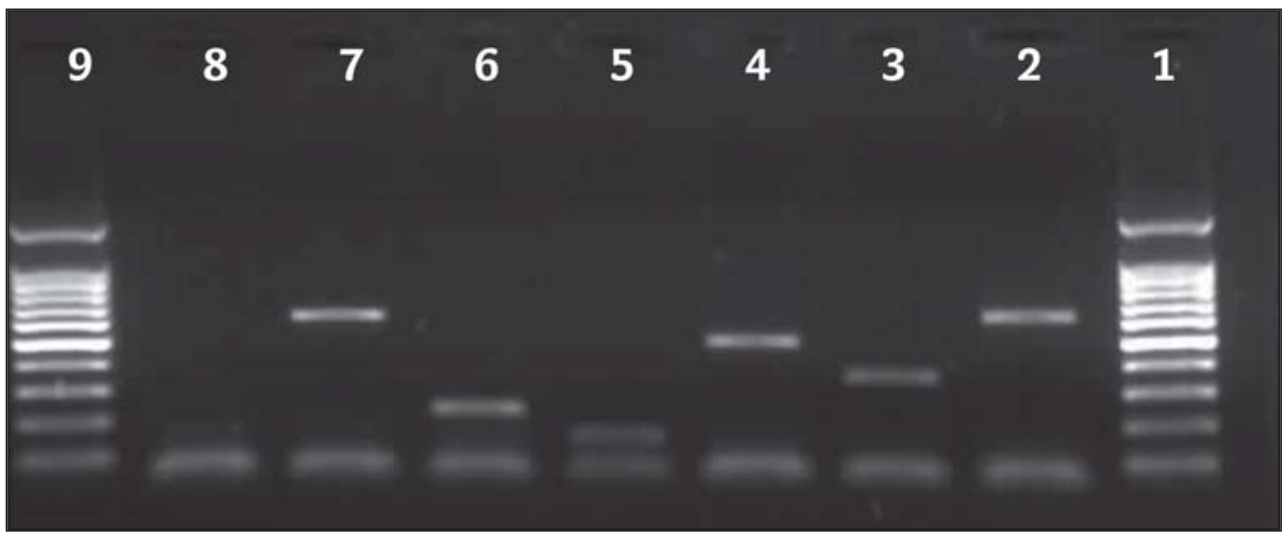

Şekil 2. Salmonella serogrup multipleks $P C R$ görüntüsü [Hat 1 ve 9: 100 bç DNA belirteci (Fermentas, SM0241); Hat 2: Salmonella Enteritidis (D grubu; 0:9, 0:9,46, 0:9,46,27); Hat 3: Salmonella Anatum (E grubu; 0:3,10, 0:3,19); Hat 4: Salmonella Infantis (C1 grubu; 0:7); Hat 5: Salmonella Kentucky (C2C3; O:8); Hat 6: Salmonella Typhimurium (0:4); Hat 7: Mukoid Salmonella izolatı; Hat 8: Negatif kontrol $\left.\left(d d \mathrm{H}_{2} \mathrm{O}\right)\right]$. 
$\mu$ l 10X PCR tamponu ( $\mathrm{MgCl}_{2}$ içermeyen), $3 \mu \mathrm{MgCl}_{2}(25 \mathrm{mM}), 0.2 \mu \mathrm{dNTP}(25 \mathrm{mM})$, her bir primerden $(5 \mathrm{pmol} / \mu \mathrm{l})$ 0.5'er $\mu \mathrm{l}, 0.25 \mu \mathrm{l}$ Taq DNA polymerase $(5 \mathrm{U} / \mu \mathrm{l}$, Fermentas; EP402), $16.05 \mu$ l deionize su, $1 \mu$ l kalıp olmak üzere toplam hacim $25 \mu$ lacak şekilde hazırlandı. Reaksiyon protokolü; $94^{\circ} \mathrm{C}^{\prime} \mathrm{de} 2 \mathrm{dk}$ ön denatürasyon, 30 döngü $94^{\circ} \mathrm{C}^{\prime}$ de 30 sn, $57^{\circ} \mathrm{C}^{\prime}$ de $40 \mathrm{sn}, 72^{\circ} \mathrm{C}^{\prime}$ de $30 \mathrm{sn}$ birleşme, $72^{\circ} \mathrm{C}^{\prime}$ de $5 \mathrm{dk}$ son uzama şeklinde gerçekleştirildi. Buna göre mukoid Salmonella türünün, yaklaşık 624 bç büyüklüğünde DNA bandı oluşturduğu ve D1 grubunda yer aldığı belirlendi (Şekil 3).

D1 grubunda olduğu saptanan izolatın, faz-1 flajellar antijenlerinin belirlenmesi için diğer bir multipleks PCR yöntemi kullanıldı ${ }^{6}$. Bu yöntem ile $H: i, H: z 10, H: I, v, H: r$ ve H:G $(g, m)$ kompleks flajellar antijenlerini çoğaltan özgül primerler ve Salmonella enterica subsp. enterica serovar Enteritidis (Salmonella Enteritidis)'in 2. fazı sergilenmediği için bu serovarı özgül olarak çoğaltan sdf1 primerlerinden yararlanıldı (Tablo I). Reaksiyon karışımı; $4 \mu \mathrm{l}$ 10X PCR tamponu ( $\mathrm{MgCl}_{2}$ içermeyen), $3 \mu \mathrm{MgCl}_{2}(25 \mathrm{mM}), 0.2 \mu \mathrm{l}$ dNTP $(25 \mathrm{mM}), 0.5 \mu \mathrm{l}$ Sense-60 (20 pmol/ $\mu \mathrm{l}), 0.5 \mu \mathrm{l}$ Antisense-i $(5 \mathrm{pmol} / \mu \mathrm{l}), 0.5 \mu \mathrm{l}$ Antisense-z10 (5 pmol/ $\mu \mathrm{l}), 0.5 \mu \mathrm{l}$ Antisense-lv ( $5 \mathrm{pmol} / \mu \mathrm{l}), 0.5 \mu \mathrm{l}$ Antisense-r $(5 \mathrm{pmol} /$ $\mu \mathrm{l}), 0.5 \mu \mathrm{l}$ Gcomplex-F (5 pmol/ $\mu \mathrm{l}), 0.5 \mu \mathrm{l}$ Gcomplex-R (5 pmol/ $\mu \mathrm{l}), 0.5 \mu \mathrm{l} \mathrm{Sdf1-F}(5$ $\mathrm{pmol} / \mu \mathrm{l}), 0.5 \mu \mathrm{l} \mathrm{Sdf1-R} \mathrm{(5} \mathrm{pmol} / \mu \mathrm{l}), 0.25 \mu \mathrm{l}$ Taq DNA polymerase $(5 \mathrm{U} / \mu \mathrm{l}$, Fermentas; EP402), $11.05 \mu$ l deionize su, $1 \mu$ l kalıp olmak üzere toplam hacim $25 \mu$ olacak şekilde hazırlandı. Reaksiyon protokolü; $94^{\circ} \mathrm{C}^{\prime} \mathrm{de} 5 \mathrm{dk}$ ön denatürasyon, 30 döngü $94^{\circ} \mathrm{C}^{\prime}$ de 30 sn, $59^{\circ} \mathrm{C}^{\prime}$ de $40 \mathrm{sn}, 72^{\circ} \mathrm{C}^{\prime}$ de 30 sn birleşme, $72^{\circ} \mathrm{C}^{\prime}$ de $5 \mathrm{dk}$ son uzama şeklinde gerçekleştirildi. Buna göre mukoid Salmonella izolatının, 500 bç büyüklüğünde DNA bandı oluşturmasıly $\mathrm{H}: \mathrm{G}$ kompleks $(\mathrm{g}, \mathrm{m})$ pozitif olduğu tespit edilirken, sdf1 primerleri ile de 300 bç'lik amplifikasyon vermesi sonucu Salmonella Enteritidis (1,9,12: g,m: -) olarak tiplendirildi (Şekil 4).

Tüm PCR döngüleri, ISı döngü cihazında (Arktik, Thermoscientific) gerçekleştirildi. Elde edilen PCR ürünlerinden $5 \mu \mathrm{l}$ alınarak, $1 \mu \mathrm{l} 6 \mathrm{X}$ "loading dye" solüsyonu yüklendi;

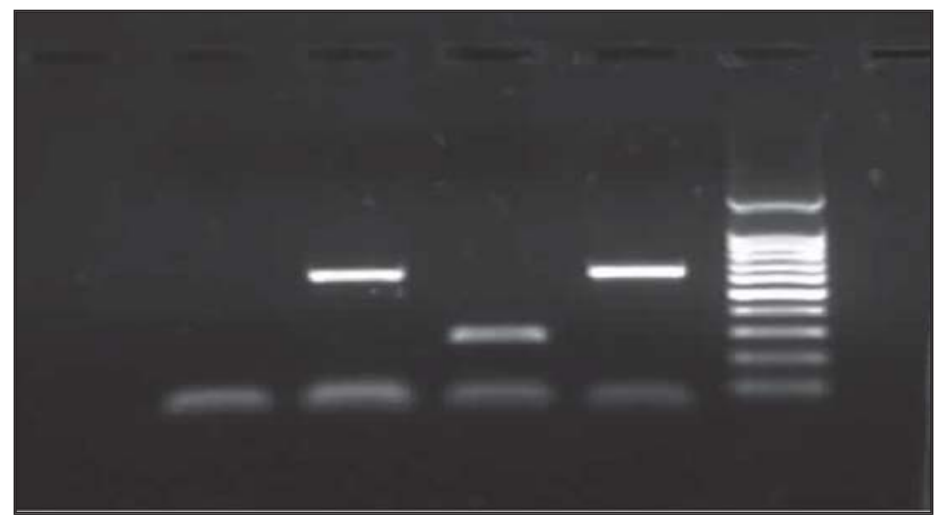

Şekil 3. Salmonella D1-E1 gruba özgül multipleks PCR görüntüsü [Hat 1: 100 bç DNA belirteci (Fermentas, SM0241); Hat 2: Salmonella Enteritidis (D1 grubu; O:9); Hat 3: Salmonella Anatum (E1 grubu; 3:10); Hat 4: Mukoid Salmonella izolati; Hat 5: Negatif kontrol $\left(\mathrm{ddH}_{2} \mathrm{O}\right)$ ]. 


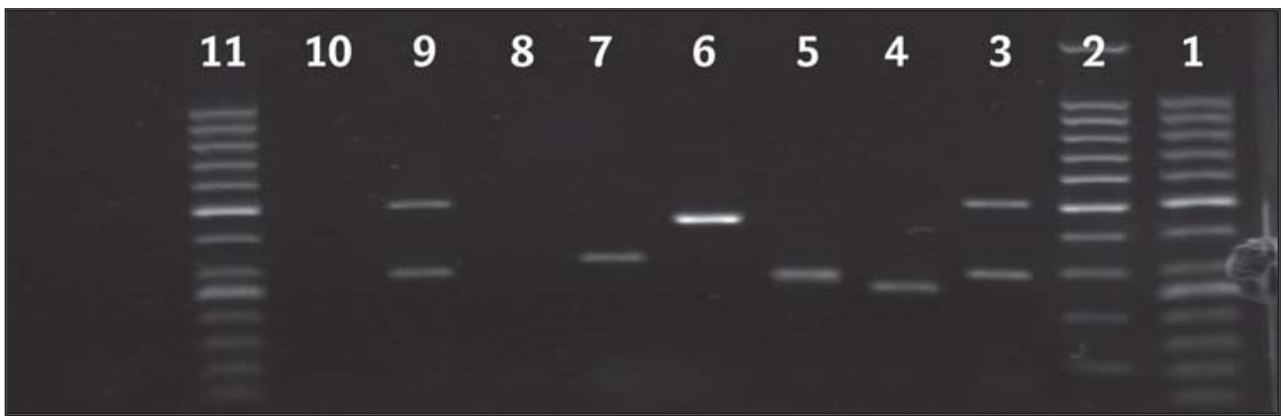

Şekil 4. Salmonella Faz-1 flajellar antijenlerinin multipleks PCR görüntüsü [Hat 1 ve 11: 50 bç DNA belirteci (Fermentas, SM0371); Hat 2: 100 bç DNA belirteci (Fermentas, SM0241); Hat 3: Salmonella Enteritidis (H:g,m); Hat 4: Salmonella Typhimurium (H:i); Hat 5: Salmonella Infantis (H:r); Hat 6: Salmonella Hadar (H:z10); Hat 7: Salmonella Brandenburg (H:I,v); Hat 8: Negatif kontrol (ddH $\left.{ }_{2} \mathrm{O}\right)$; Hat 9: Mukoid Salmonella izolatı; Hat 10: Boş]

$0.5 \mathrm{\mu l} / \mathrm{ml}$ etidyum bromür ile boyanan \%2'lik agaroz jelde $100 \mathrm{~V}$ elektrik akımında $45 \mathrm{dk}$ yürütülerek elektroforez işlemi yapıldı. Agaroz jel UV translüminatöre transfer edilerek, oluşan bantlar DNA belirteci ve pozitif kontroller yardımıyla UV ışığı altında görüntülendi ve değerlendirildi.

Tür düzeyinde tanımlanan suşun antibiyotik duyarlılık testi $\mathrm{CLSI}^{7}$ önerilerine uygun olarak, disk difüzyon yöntemiyle yapıldı ve izolatın ampisilin, kloramfenikol, seftriakson, siprofloksasin ve trimetoprim-sülfametoksazole (Bioanalyse, Türkiye) duyarlı olduğu saptandı.

\section{TARTIŞMA}

Insan ve hayvanlarda yaygın enfeksiyon etkeni olan Salmonella serotiplerinden, özellikle Salmonella enterica subsp. enterica serovar Enteritidis (Salmonella Enteritidis)'in görülme sıklığı dünya genelinde giderek artmış ve ülkemizde de yıllardan beri insan enfeksiyonlarında en sık karşılaşılan serotip olmuştur ${ }^{8}$. S.Enteritidis'in hem gastroenterit olgularından hem de bağırsak dışı enfeksiyonlardan sıklıkla izole edildiği bilinmektedir $^{8}$. Genellikle gıda kaynaklı salgınlara yol açan, ancak sporadik olarak da saptanan S.Enteritidis'in, Batı Avrupa'da "Enterik Enfeksiyonların Ulusal Sürveyans Ağı (Enternet)"na ait ulusal referans laboratuvarlarında en sık tanımlanan serotip olduğu bildirilmektedir ${ }^{9}$.

Literatürde, mukoid Salmonella izolatlarıyla ilgili bildirime pek rastlanmamaktadır. Almanya'dan bildirilen, idrar kültüründen izole edilen mukoid formda bir Salmonella suşunun tanımlanmasında yaşanan benzer zorluklar nedeniyle, araştırmacılar, bakterinin $\mathrm{M}$ formdan $\mathrm{N}$ ya da $\mathrm{T} 1$ forma transformasyonunu gerçekleştirerek antiserumlarla aglütinasyonu sağlayabildiklerini bildirmişlerdir ${ }^{2}$. Bu çalışmada, transformasyon bakterinin oda ısısında bekletilmesi veya $U$ tüpte besiyerine pasaj yapılması yöntemiyle sağlanmıştır². Bu yöntemi örnek alarak, izolatımızı antiserumlarla yeniden karşılaştırdığımızda da aglütinasyonun yine negatif olduğu gözlenmiştir. 
Çalışmamızla benzer olarak; Herrera-Leon ve arkadaşları ${ }^{4}$ özellikle O (somatik) antijenini kaybedip kaba (rough) suşa dönüşen veya flajellar antijenlerini eksprese etmeyen ve monofazik veya hareketsiz duruma geçen Salmonella'ları konvansiyonel yöntemlerle tanımlayamamış, ancak multipleks PCR (MPCR) ile tespit edebildiklerini bildirmişlerdir. Yaklaşık 20 yıldır Salmonella izolatlarının PCR tabanlı yöntemlerle karakterizasyonu üzerine çalışmalar yapılmaktadır ${ }^{10-12}$. Bu yöntemler bazı çalışmalarda direkt somatik antijenlerin $^{4,5,13}$ bazılarında ise flajellar antijenlerin ${ }^{6,14,15}$ tespit edilmesine yöneliktir. Herrera-Leon ve arkadaşlarının ${ }^{4}$ çalışmasında, mPCR ile 500 Salmonella izolatının 423'ü serogruplandırılabilmiş; ayrıca konvansiyonel yöntemlerle serotiplendirilemeyen beş (biri otoaglütinasyon veren, dördü hareketsiz olan) S.Enteritidis suşunun tiplendirilmesi mümkün olmuştur. Bu araştırıcılar, klasik ve moleküler serotiplendirme yöntemleri arasındaki korelasyonu \%99.2 olarak bildirmişlerdir ${ }^{4}$. Herrera-Leon ve arkadaşları ${ }^{6}$ bir başka çalışmalarında da, optimize ettikleri faz-1 mPCR ile Salmonella izolatlarının \%80'ini doğru olarak tespit edebildiklerini rapor etmişlerdir. Echeita ve arkadaşları ${ }^{15}$ ise, 10 primer çifti ile 49 farklı serotipe ait toplam 140 Salmonella izolatı ile yaptıkları çalışmada, faz-2 antijenlerinin saptanmasında mPCR yönteminin duyarlılık ve özgüllüğünü \%100 olarak bildirmişlerdir. Gerek S.Enteritidis'in faz-2 flajellar antijenini eksprese etmemesi, gerekse S.Enteritidis'e özgül sdf1 primerleri faz-1 mPCR yönteminde kullanmış olmamız nedeniyle, çalışmamızda faz 2 antijenlerine bakmaya gerek kalmamıştır ${ }^{6}$.

Çalışmamızda, nefrolitiazisli bir olgunun idrar örneğinden izole edilen mukoid Salmonella sp. suşu, mPCR ile S.Enteritidis (1,9,12:9,m:-) olarak tiplendirilmiş ve bu izolatın konvansiyonel serotiplendirme ile tiplendirilmesinin oldukça zor, hatta olanaksız olduğu düşünülmüştür. Dolayısıyla PCR, somatik, flajellar antijenlerin eksprese edilmediği, kaba veya mukoid formda Salmonella izolatları ile karşılaşılan durumlarda hızlı ve güvenilir alternatif bir yöntem olarak, konvansiyonel serotiplendirmeye destek olacaktır. Sonuç olarak moleküler tiplendirmenin, Salmonella sürveyansının duyarlılık ve özgüllüğünü artırmakta ve geleneksel tanımlama yöntemleriyle saptanamayacak ve salgınları tetikleyebilecek olguların zamanında doğru tespit edilmesinde büyük rol oynayacağı akılda tutulmalıdır.

\section{TEŞEKKÜR}

İzole ettiğimiz suşun Vitek MS MALDI-TOF sistemi (bioMérieux, Fransa) ile çalışılmasındaki katkılarından dolayı bioMérieux Firması'ndan Dr. Ahmet Süel'e teşekkürlerimizi sunarız.

\section{KAYNAKLAR}

1. Nataro JP. Escherichia, Shigella and Salmonella, pp: 682-3. In: Murray PR, Baron EJ, Jorgensen JH, Pfaller MA, Yolken RH (eds), Manual of Clinical Microbiology, 2009, $9^{\text {th }}$ ed. American Society for Microbiology, Washington, DC.

2. Wuthe $\mathrm{HH}$, Aleksic S, Podschun $\mathrm{R}$, et al. Urinary tract infection due to a mucoid (M) form of Salmonella. A new transformation from M form into T1 form. Zhl Bakt 1992; 277(1): 74-9. 
3. Rahn K, De Grandis SA, Clarke RC, et al. Amplification of invA gene sequence of Salmonella typhimurium by polymerase chain reaction as specific method of detection of Salmonella. Mol Cell Probes 1992; 6(4): 271-9.

4. Herrera-Leon S, Ramiro R, Arroyo M, Diez R, Usera MA, Echeita MA. Blind comparison of traditional serotyping with three multiplex PCRs for the identification of Salmonella serotypes. Res Microbiol 2007; 158(2): 122-7.

5. Hong Y, Liu T, Lee MD, et al. Rapid screening of Salmonella enterica serovars Enteritidis, Hadar, Heidelberg and Typhimurium using a serologically-correlative allelotyping PCR targeting the $\mathrm{O}$ and $\mathrm{H}$ antigen alleles. BMC Microbiol 2008; 8: 178.

6. Herrera-Leon S, McQuiston JR, Usera MA, Fields PI, Garazier J, Echeita MA. Multiplex PCR for distinguishing the most common phase-1 flagellar antigens of Salmonella spp. J Clin Microbiol 2004; 42(6): 2581-6.

7. Clinical and Laboratory Standards Institute. Antimikrobik duyarlılık testleri için uygulama standartları. Yirmi ikinci Bilgi Eki, M100-S22, 2012. Gür D (Çeviri ed), Türk Mikrobiyoloji Cemiyeti Yayını, İstanbul.

8. Erdem B, Hasçelik G, Gedikoğlu S, et al. Salmonella enterica serotypes and Salmonella infections: a multicenter study covering ten provinces in Turkey. Mikrobiyol Bul 2004; 38(3): 173-86.

9. Fisher IS. Enter-net participants. Dramatic shift in the epidemiology of Salmonella enterica serotype Enteritidis phage types in western Europe, 1998-2003 results from the Enter-net international salmonella database. Euro Surveill 2004; 9(11): 43-5.

10. Aarts HJ, Van Lith LA, Keijer J. High resolution genotyping of Salmonella strains by AFLP-fingerprinting. Lett Appl Microbiol 1998; 26(2): 131-5.

11. Garaizar J, Lopez-Molina N, Laconcha I, et al. Suitability of PCR fingerprinting, infrequent-restriction-site PCR, and pulsed-field gel electrophoresis, combined with computerized gel analysis, in library typing of Salmonella enterica serovar Enteritidis. Appl Environ Microbiol 2000; 66(12): 5273-81.

12. Lindstedt BA, Heir E, Vardund T, Kapperud G. Fluorescent amplified-fragment length polymorphism genotyping of Salmonella enterica subsp. enterica serovars and comparison with pulsed-field gel electrophoresis typing. J Clin Microbiol 2000; 38(4): 1623-7.

13. Luk JM, Kongmuang U, Reeves PR, Lindberg AA. Selective amplification of abequose and paratose synthase genes $(\mathrm{rbb})$ by polymerase chain reaction for identification of Salmonella major serogroups (A, B, C2, and D). J Clin Microbiol 1993; 31(8): 2118-23.

14. Echeita MA, Usera MA. Rapid identification of Salmonella spp. phase 2 antigens of the $\mathrm{H} 1$ antigenic complex using "multiplex PCR". Res Microbiol 1998; 149(10): 757-61.

15. Echeita MA, Herrera S, Garaizar J, Usera MA. Multiplex PCR- based detection and identification of the most common Salmonella-second-phase flagellar antigens. Res Microbiol 2002; 153(2): 107-13. 